\title{
Qualidade do Feno de Brachiaria decumbens Stapf. Submetido ao Tratamento com Amônia Anidra ou Uréia ${ }^{1}$
}

\author{
Leonardo de Oliveira Fernandes ${ }^{2}$, Ricardo Andrade Reis ${ }^{3}$, Luis Roberto de Andrade Rodrigues ${ }^{3}$, \\ Ivan Luz Ledic ${ }^{4}$, Renato Jácomo Manzan ${ }^{4}$
}

RESUMO - O experimento foi conduzido na fazenda Pedrões, no município de Uberaba-MG, para avaliar a qualidade do feno de Brachiaria decumbens enfardado após a queda de sementes. Os fenos foram submetidos aos seguintes tratamentos: feno não tratado, feno tratado com amônia anidra $\left(3,0 \% \mathrm{NH}_{3}\right.$ na MS), feno tratado com uréia $(5,0 \%$ na MS). A composição química, a digestibilidade dos fenos e o desempenho de novilhos foram avaliados usando um delineamento em blocos completos casualisados com três tratamentos e seis repetições. A amonização utilizando $\mathrm{NH}_{3}$ ou uréia aumentou o conteúdo de proteína bruta e a DIVMS. O tratamento com $\mathrm{NH}_{3}$ reduziu os conteúdos de FDN e FDA, e a aplicação de uréia reduziu os conteúdos de hemicelulose e lignina. A amonização não afetou os valores de nitrogênio insolúvel em detergente neutro e nitrogênio insolúvel em detergente ácido. Novilhos recebendo feno de brachiaria e farelo de soja (1,08 kg/dia de MS), feno tratado com amônia e milho grão (1,14 kg/dia de MS) e feno tratado com uréia e milho grão (1,14 kg/ dia de MS) apresentaram consumo de MS de 1,97; 2,23 e 1,90\% do peso vivo e ganhos de peso de 0,$60 ; 0,53$ e $0,37 \mathrm{~kg} / \mathrm{dia}$, e conversão alimentar 10,$8 ; 12,8$ e $16,9 \mathrm{~kg} \mathrm{MS} / \mathrm{kg}$ de ganho de peso, respectivamente.

Palavras-chave: amônia anidra, amonização, composição química, consumo, ganho de peso, uréia

\section{Quality of Ammoniated Brachiaria decumbens Hay}

\begin{abstract}
The experiment was conducted at farm Pedrões of the F.C. Agropecuária, located in Uberaba-MG to evaluate the quality of Brachiaria decumbens hays harvested after seed ripening. The hays were submitted to the following treatments: control, anhydrous ammonia $\left(3.0 \% \mathrm{NH}_{3}\right.$ in the $\left.\mathrm{DM}\right)$, and urea $(5.0 \%$ in the $\mathrm{DM})$. The chemical composition, digestibility hays and the performance of steers were evaluated using a complete randomized block design with three treatments and six replications. The ammoniation either with $\mathrm{NH}_{3}$ or urea increased the CP content and the IVDMD. The $\mathrm{NH}_{3}$ treatment reduced the contents of NDF and ADF, and the urea application reduced the contents of hemicellulose and lignin. The ammoniation did not affect the neutral detergent insoluble nitrogen, and acid detergent insoluble nitrogen values. Steers receiving Brachiaria hay plus soybean meal (1.08 kg/day of DM), hay treated with $\mathrm{NH}_{3}$ plus corn meal $(1.14 \mathrm{~kg} /$ day of DM) and hay treated with urea plus corn meal (1.14 kg/day of DM) showed DM intake of 1.97 ; 2,23 and $1.90 \% \mathrm{BW}$; weight gains of $0.60 ; 0.53$ and $0.37 \mathrm{~kg} /$ day, and feed conversion of $10.8 ; 12.8$ and 16.9 of $\mathrm{kg} \mathrm{DM} / \mathrm{kg} \mathrm{WG}$, respectively.
\end{abstract}

Key Words: anhydrous ammonia, ammoniation, chemical composition, intake, weight gain, urea

\section{Introdução}

A alimentação de ruminantes é um importante componente econômico dentro do processo produtivo e alternativas para a suplementação, que reflitam na diminuição de custos, tem sido utilizadas. Os resíduos de culturas anuais de verão e de inverno e fenos de baixa qualidade, em conseqüência da fenação ou armazenamento inadequados, são normalmente utilizados na dieta de bovinos.

Deve-se considerar, todavia, que esses volumosos são de baixa qualidade, pois apresentam alto conteúdo de parede celular (valores acima de $60,0 \%$ ) e de fibra em detergente ácido (FDA acima de $40,0 \%$ ) e baixos teores de proteína bruta (PB abaixo de $6,0 \%$ ), de minerais e de vitaminas, sendo a digestibilidade da matéria seca baixa $(40,0$ a $50 \%)$, resultando em baixos níveis de consumo (Reis \& Rodrigues, 1994).

Como forma de aumentar a eficiência de utilização desses volumosos, têm sido testados tratamentos biológicos, físicos e químicos. Vários métodos químicos têm sido avaliados, destacando-se o uso do hidróxido de sódio, de cálcio, de potássio e de amônio, a amônia anidra e a uréia, como fonte de amônia (Sundstol \& Coxworth, 1984; Garcia et al., 1988).

\footnotetext{
${ }^{1}$ Parte da tese de Mestrado apresentada à FCAV-UNESP, Jaboticabal pelo primeiro autor. Pesquisa financiada pela FC Agropecuária/ CNPq/FAPESP.

2 Doutorando FCAV/UNESP-Jaboticabal.

2 Pesquisador da EPAMIG, professor da FAZU, 38001-970, Uberaba-MG. E.mail: leonardo@epamiguberaba.com.br

3 Professores do Departamento de Zootecnia da FCAV-UNESP, 14870-000, Jaboticabal-SP

${ }^{4}$ Pesquisadores EMBRAPA/EPAMIG, MSc, 38001-970, Uberaba-MG.
} 
A amonização de volumosos com a utilização de amônia anidra $\left(\mathrm{NH}_{3}\right)$ ou com uréia promove alterações na composição da fração fibrosa com a solubilização da hemicelulose, resultando em diminuição no conteúdo de FDN (Pereira et al., 1990), aumentando os teores de nitrogênio não protéico (Bonjardin et al., 1992; Queiroz et al.,1992; Rosa et al., 1996). De acordo com Reis et al.(1995b), estas alterações permitem aumentar a digestibilidade de volumosos amonizados, ocorrendo também um incremento no consumo de matéria seca de animais alimentados com volumosos tratados.

A ação da amônia anidra sobre a forragem promove desestruturação e rompimento no complexo formado pelos componentes da fração fibrosa (celulose, hemicelulose e lignina), propiciando aos microrganismos do rúmen uma maior área de exposição, aumentando o grau de utilização das diferentes frações de fibra.

Trabalhos de pesquisa, conduzidos com fenos de gramíneas forrageiras tropicais, colhidas no estágio de desenvolvimento avançado e tratados com $\mathrm{NH}_{3}$ ou uréia, mostram diminuição nos teores de FDN, hemicelulose e aumento no conteúdo de PB (Reis \& Rodrigues, 1994; Pereira et al., 1993).

A melhor condição corporal dos animais alimentados com forragens amonizadas tem sido correlacionada positivamente com um maior consumo de matéria seca. O aumento da digestibilidade da forragem após tratamento e conseqüente aumento na disponibilidade da energia, resulta numa digestão mais rápida e menor tempo de passagem do alimento pelo trato digestivo, o que propicia, finalmente, maior consumo e melhor desempenho animal (Berger et al., 1994).

Em experimento de alimentação de novilhos Nelore, Reis et al. (1995b) avaliaram os efeitos da amonização do feno de Brachiaria brizantha cv. Marandu e da suplementação protéica e, ou, protéica/ energética sobre o ganho de peso de bovinos. O ganho de peso dos animais que consumiam feno tratado foi superior quando comparado aos do feno não tratado. Os autores ressaltam que os animais que foram alimentados com feno tratado, suplementado com milho e farelo de algodão, ganharam $0,37 \mathrm{~kg} / \mathrm{dia}$ a mais do que aqueles alimentados com feno não tratado e concentrado. A ingestão de MS foi maior nos animais alimentados com os volumosos submetidos à amonização $(2,37 ; 2,82 \% \mathrm{PV}$, respectivamente para o volumoso não tratado e tratado).
Este trabalho foi desenvolvido com a finalidade de avaliar as modificações na composição química e digestibilidade in vitro da matéria seca do feno de Brachiaria decumbens Stapf tratado com amônia anidra ou com uréia, bem como o desempenho de bovinos confinados alimentados com rações formuladas utilizando esses volumosos.

\section{Material e Métodos}

O experimento foi conduzido na Fazenda Pedrões pertencente à F.C. Agropecuária Ltda., no município de Uberaba-MG, localizado a $19^{\circ} 45^{\prime} 56^{\prime \prime}$ de latitude sul e $47^{\circ} 57^{\prime}$ de longitude oeste, numa altitude de $774 \mathrm{~m}$. O clima da região é do tipo tropical semi-úmido, temperatura média de $21,4^{\circ} \mathrm{C}$ e a umidade relativa do ar média é de $71,4 \%$.

A fenação foi mecanizada sendo todas as operações realizadas na primeira semana de junho de 1997 , após a queda de sementes do capim Brachiaria decumbens. A forragem foi enfardada obtendo-se fardos com aproximadamente $100 \mathrm{~kg}$, medindo $1,10 \mathrm{~m}$ de comprimento e $0,90 \mathrm{~m}$ de diâmetro. A seguir os fardos foram transportados para a Fazenda Pedrões e armazenados em galpões arejados até o tratamento químico.

Em 27/06/97, foram coletadas amostras para as determinações dos teores de matéria seca, possibilitando o cálculo das quantidades de amônia anidra e de uréia a serem aplicadas. Por ocasião do tratamento químico, a forragem apresentava $93 \%$ de matéria seca.

O tratamento químico do feno foi realizado em 19/07/97, utilizando-se amônia anidra $\left(\mathrm{NH}_{3}\right)$ ou uréia.

A forragem foi pesada, empilhada sobre lona plástica, e com o uso de outra lona plástica para a cobertura, foi possível mantê-la armazenada em condições hermeticamente fechadas ao longo do período de tratamento.

O tratamento do feno do capim $B$. decumbens com amônia $\left(\mathrm{NH}_{3}\right)$ foi realizado segundo Sundstol \& Coxworth (1984). A amônia anidra foi injetada nos fardos na quantidade de 3,0\% em relação ao peso seco, compondo duas pilhas de $3720 \mathrm{~kg}$ de MS de feno, armazenadas no campo. A quantidade de amônia anidra aplicada foi conferida com a pesagem contínua do cilindro, em balança com capacidade de $500 \mathrm{~kg}$ e precisão de 100 gramas.

O tratamento com uréia foi realizado sob lona plástica de forma semelhante ao descrito para o tratamento com amônia anidra, sendo utilizados $7440 \mathrm{~kg}$ 
de matéria seca de feno, divididos em duas pilhas. A uréia foi diluída em água (1 parte de uréia para 3,4 partes de água). Para cada pilha de fardos de $3720 \mathrm{~kg}$ de matéria seca foram adicionados $186 \mathrm{~kg}$ de uréia (5,0\% da MS), dissolvidos em 640 litros de água. Tal quantidade de água foi calculada para elevar o conteúdo de umidade do volumoso para $20 \%$. A uréia foi distribuída por aspersão, utilizando um regador, na proporção de $5,0 \%$ do peso seco do feno, equivalente a quantidade de nitrogênio adicionada com a amônia anidra (Dolberg, 1992).

Uma quantidade de feno equivalente a $7440 \mathrm{~kg}$ de matéria seca do volumoso, não tratado, foi armazenada em galpão arejado, até o início da avaliação do desempenho animal.

Durante o período de tratamento os dados climatológicos médios observados foram os seguintes: temperatura média de $18,6^{\circ} \mathrm{C}$; umidade relativa do ar de $54,7 \%$, não ocorrendo chuvas durante o período.

Após o tratamento com $\mathrm{NH}_{3}$ ou com uréia, a forragem permaneceu 30 dias sob lona plástica, hermeticamente fechada. Após este período as pilhas de fardos foram abertas (18/08/97), submetidas a três dias de aeração para eliminação do excesso de $\mathrm{NH}_{3}$, que não reagiu com os volumosos, procedendo-se a seguir a amostragem da forragem para efetuar as determinações químicas.

As amostras retiradas foram congeladas, em seguida moídas, para se evitar as perdas de nitrogênio amoniacal durante a secagem em estufa.

As determinações químicas dos volumosos foram realizadas no Laboratório de Nutrição Animal da FCAV - UNESP com o objetivo de se determinar os teores de MS, de nitrogênio total, de fibra em detergente neutro (FDN), de fibra em detergente ácido (FDA), de hemicelulose, de celulose e de lignina, segundo Silva (1990). A digestibilidade in vitro da matéria seca (DIVMS) foi obtida pela técnica de duas etapas, usando pepsina ácida conforme Tilley \& Terry citados por Silva (1990).

Os teores de nitrogênio insolúvel em detergente neutro (NIDN) e de nitrogênio insolúvel em detergente ácido (NIDA) dos fenos foram dosados no resíduo após o tratamento das amostras (detergente ácido ou neutro) segundo a técnica de Van Soest et al. (1983).

Com base nos resultados das análises químicas, foi calculada a dieta fornecida aos bovinos de acordo com AFRC (1995), com o propósito de se promover o máximo crescimento microbiano. Foram avaliados três tratamentos, sendo $\mathrm{T} 1=$ Feno não tratado mais farelo de soja (1,08 kg/animal/dia de MS); T2= Feno amonizado com amônia anidra mais milho grão moído $(1,147 \mathrm{~kg} /$ animal/dia de MS); T3=Feno amonizado com uréia mais milho grão moído (1,147 kg/animal/dia de MS). Nos tratamentos 2 e 3 a quantidade de milho foi a suficiente para fornecer a mesma quantidade de energia fermentável fornecida pelo farelo de soja no T1 (AFRC, 1995). Os animais receberam feno e mistura mineral à vontade, procurando manter as sobras de feno entre 10 e $15 \%$ da quantidade fornecida.

Foram utilizados 36 bovinos, sendo 24 da raça Nelore e 12 da raça Brahman, com peso médio de $230 \mathrm{~kg}$, alojando-se dois bovinos por baia em sistema de confinamento exclusivo. O experimento durou 98 dias, sendo 14 dias de adaptação e 84 dias de avaliação. As pesagens dos animais foram realizadas após jejum de 14 horas, a cada 28 dias, verificando o ganho de peso e a conversão alimentar.

Os dados referentes à composição química e digestibilidade dos fenos foram analisados de acordo com o delineamento em blocos casualizados com seis repetições, sendo consideradas as camadas de fardos dentro das pilhas. Os valores de consumo de matéria seca (\% PV), ganho de peso por animal (kg/animal/ dia) e conversão alimentar (kg MS/kg PV) foram analisados segundo o delineamento em blocos casualizados, com três tratamentos, três blocos e duas repetições por bloco, obtendo-se dezoito parcelas, sendo que cada parcela foi constituída de dois animais. As médias foram comparadas pelo teste de Tukey a $5,0 \%$ de probabilidade.

Considerando os custos inerentes ao processo de fenação, amonização e concentrado, determinou-se o custo de produção da arroba. Para realização dos cálculos foram considerados: rendimento de carcaça de 50,0\%; preço do milho de $\mathrm{R} \$ 0,13 / \mathrm{kg}$; preço do farelo de soja de $\mathrm{R} \$ 0,34 / \mathrm{kg}$; preço da amônia anidra de $\mathrm{R} \$ 3,40 / \mathrm{kg}$; preço da uréia de $\mathrm{R} \$ 0,50 / \mathrm{kg}$; custo do volumoso de R \$30,00/tonelada (processo de fenação); custo da lona plástica de $\mathrm{R} \$ 13,00 /$ tonelada de feno tratado; custo da mão-de-obra para o tratamento químico de $\mathrm{R} \$ 3,75 /$ tonelada.

\section{Resultados e Discussão}

Observando os dados apresentados nas Tabelas 1 e 2, verifica-se que houve mudanças acentuadas na fração fibrosa do feno amonizado, evidenciando diminuição $(\mathrm{P}<0,05)$ nos teores de FDN e FDA apenas para os fenos tratados com $\mathrm{NH}_{3}$. 
Tabela 1 - Composição química e digestibilidade in vitro da MS (DIVMS) dos fenos de Brachiaria decumbens amonizados (\% MS)

Table 1 - Chemical composition and digestibility of the ammoniated Brachiaria decumbens hays

\begin{tabular}{|c|c|c|c|c|}
\hline & & $\begin{array}{c}\text { Tratamentos } \\
\text { Treatments }\end{array}$ & & \\
\hline & $\begin{array}{c}\mathrm{NT}(\% \mathrm{MS}) \\
\text { Control }(\% D M)\end{array}$ & $\begin{array}{l}\mathrm{NH}_{3}(3,0 \% \mathrm{MS}) \\
\mathrm{NH}_{3}(3.0 \% \mathrm{DM})\end{array}$ & $\begin{array}{l}\text { Uréia }(5,0 \% \mathrm{MS}) \\
\text { Urea }(5.0 \% \mathrm{DM})\end{array}$ & $\mathrm{CV}(\%)$ \\
\hline $\mathrm{PB}$ & $2,82^{\mathrm{c}}$ & $9,66^{\mathrm{b}}$ & $12,02^{\mathrm{a}}$ & 9,81 \\
\hline $\begin{array}{l}\text { FDN } \\
N D F\end{array}$ & $83,91^{\mathrm{a}}$ & $79,44^{b}$ & $81,98^{\mathrm{a}}$ & 1,96 \\
\hline $\begin{array}{l}\text { FDA } \\
A D F\end{array}$ & $51,73^{\mathrm{a}}$ & $48,12^{b}$ & $52,73^{\mathrm{a}}$ & 2,95 \\
\hline $\begin{array}{l}\text { Hemicelulose } \\
\text { Hemicellulose }\end{array}$ & $32,18^{\mathrm{a}}$ & $31,32^{\mathrm{a}}$ & $29,25 b$ & 4,14 \\
\hline $\begin{array}{l}\text { Celulose } \\
\text { Celulose }\end{array}$ & $42,39^{b}$ & $40,16^{\mathrm{b}}$ & $45,50^{\mathrm{a}}$ & 3,93 \\
\hline $\begin{array}{l}\text { Lignina } \\
\text { Lignin }\end{array}$ & $9,33^{\mathrm{a}}$ & $7,96^{\mathrm{ab}}$ & $7,23 b$ & 12,39 \\
\hline $\begin{array}{l}\text { NIDN } \\
\text { NDIN }\end{array}$ & $0,34^{\mathrm{a}}$ & $0,45^{\mathrm{a}}$ & $0,39^{\mathrm{a}}$ & 22,80 \\
\hline $\begin{array}{l}\text { NIDA } \\
A D I N\end{array}$ & $0,28^{\mathrm{a}}$ & $0,33^{\mathrm{a}}$ & $0,29^{\mathrm{a}}$ & 15,20 \\
\hline $\begin{array}{l}\text { DIVMS } \\
\text { IVDMD }\end{array}$ & $47,55 \mathrm{c}$ & $59,61^{\mathrm{a}}$ & $54,19^{b}$ & 4,01 \\
\hline
\end{tabular}

Médias na mesma linha seguidas de letras iguais não diferem entre si, pelo teste de Tukey $(P>0,05)$.

Means in the row followed by the same letter do not differ $(P>.05)$.

Em alguns trabalhos (Reis et al., 1995b; Pereira et al.,1993) pode-se observar que uma das principais modificações na composição química da fração fibrosa de volumosos amonizados é a diminuição no conteúdo de FDN, como conseqüência da solubilização da hemicelulose.

$\mathrm{Na}$ maioria dos trabalhos consultados referentes à amonização de fenos, não foram observadas alterações no conteúdo de FDA (Reis \& Rodrigues, 1994), resultados que contrastam com o obtido no presente experimento quando foi utilizada a $\mathrm{NH}_{3}$, não se observando o mesmo para o tratamento com uréia. Encontram-se na literatura diferentes resultados referentes ao conteúdo de FDA, celulose e lignina, entre espécies forrageiras como efeito do tratamento com $\mathrm{NH}_{3}$ ou uréia (Pereira et al.,1993; Reis et al.,1995b).

Os valores de FDN e FDA estão sujeitos a variações, em função de qualquer alteração que ocorra nos conteúdos de celulose, hemicelulose e lignina. A redução dos teores de $\mathrm{FDN}$ em resposta à amonização pode ser atribuída à diminuição nos conteúdos de hemicelulose e lignina em decorrência da hidrólise alcalina (Sundstol \& Coxworth, 1984).

De fato, pode-se observar na Tabela 1, pelas análises efetuadas, que o tratamento utilizando uréia, resultou em diminuição significativa $(\mathrm{P}<0,05)$ nos teores de hemicelulose e de lignina. Para o tratamento utilizando $\mathrm{NH}_{3}$, apesar de não ter ocorrido diferença significativa $(\mathrm{P}>0,05)$, pode-se observar a tendência de diminuição do conteúdo de hemicelulose. Pereira et al. (1993), trabalhando com amonização do feno de Brachiaria decumbens Stapf (3,0\% de $\mathrm{NH}_{3}$ na MS), verificaram diminuição no conteúdo de hemicelulose de 31,2 para $26,5 \%$.

A amonização, utilizando uréia, promoveu diminuição $(\mathrm{P}<0,05)$ no teor de lignina do feno. Contudo não houve diferença entre os tratamentos tratados com $\mathrm{NH}_{3}$ ou uréia (Tabela 1). Na literatura encontrase grande contradição nos resultados da amonização sobre o conteúdo de lignina, sendo que alguns demonstram diminuição no conteúdo (Queiroz et al., 1992). Rosa et al.(1998) observaram diminuição no conteúdo de lignina de $24,6 \%$, em resposta ao tratamento do feno com uréia.

Foi observado conteúdo de celulose $(\mathrm{P}<0,05)$ mais elevado para o feno tratado com uréia (Tabela 1). Para o feno tratado com $\mathrm{NH}_{3}$, observou-se ligeira tendência do conteúdo de celulose em diminuir $(\mathrm{P}>0,05)$. $\mathrm{O}$ resultado desta pesquisa está de acordo com os dados 
de outros trabalhos conduzidos nas mesmas condições do presente estudo. Bonjardim et al. (1992) trabalhando com a amonização do feno de coast cross e estrela da África e Rosa et al. (1996) estudando a amonização do feno de Brachiaria decumbens Stapf não observaram alterações nos teores de celulose.

Os dados apresentados na Tabela 1 evidenciaram que a amonização aumentou $(\mathrm{P}<0,05)$ o teor de proteína bruta $(\mathrm{PB})$ dos fenos tratados. O aumento no teor de PB foi de 6,84 e 9,20 unidades percentuais, respectivamente, para o feno tratado com $\mathrm{NH}_{3}$ e uréia, sendo observada diferença entre os mesmos.

Os resultados referentes aos conteúdos de compostos nitrogenados têm sido observado como o mais consistente nos trabalhos sobre amonização de volumosos. Berger et al. (1994) afirmam que, de maneira geral, observam-se aumentos de 5 a 6 unidades percentuais no conteúdode $\mathrm{PB}$, como resultado da técnica da amonização de forragem de baixa qualidade.

Estes resultados confirmam os de Reis et al. (1995a) que amonizando o feno de Brachiaria brizantha cv. Marandu com uréia ou $\mathrm{NH}_{3}$, observaram incrementos no teor de PB de 15,5 e 8,3 unidades percentuais, respectivamente.

Os teores de NIDN e NIDA (Tabela 1) não foram alterados $(\mathrm{P}>0,05)$ pelo processo da amonização. Este resultado contrasta com diversos trabalhos reportados na literatura, que demonstram aumento no teor de NIDA como consequência da amonização (Rosa et al., 1996). A importância do conhecimento da modificação no teor de NIDA é justificada pelo fato do nitrogênio presente nesta forma permanecer indisponível para o animal (AFRC, 1995).

Os valores de retenção de nitrogênio total foram maiores para o tratamento com uréia (Tabela 2), sendo registrados 44,7 e $65,3 \%$, respectivamente para os fenos tratados com $\mathrm{NH}_{3}$ ou uréia. Rosa et al. (1996), avaliando a amonização do feno de Brachiaria decumbens Stapf cv. Basilisk, observaram valores de retenção de nitrogênio de $50,8 \%$ e $53,6 \%$, quando aplicaram $3,0 \% \mathrm{de} \mathrm{NH}_{3}$ e $5,4 \%$ de uréia, respectivamente.

A maior retenção de nitrogênio na forma de uréia pode ser explicada pelo maior conteúdo de umidade do feno amonizado desta forma, pois procurou-se elevar a umidade para $20,0 \%$ através da adição de água, durante o tratamento, pois o feno apresentava naquela ocasião 93,0\% de MS. Segundo Dolberg (1992), Reis \& Rodrigues (1994) a retenção de nitrogênio varia em função da quantidade de $\mathrm{NH}_{3}$ ou
Tabela 2 - Teores de nitrogênio total, de nitrogênio adicionado, de nitrogênio fixado (\% MS), e de nitrogênio fixado (\% do adicionado) do feno de Brachiaria decumbens amonizado

Table 2 - Total nitrogen (TN) content, applied nitrogen, and total fixed nitrogen in ammoniated Brachiaria decumbens hays

\begin{tabular}{|c|c|c|c|}
\hline \multirow[b]{2}{*}{$\begin{array}{l}\text { Frações de } \mathrm{N} \\
N \text { fractions }\end{array}$} & \multicolumn{3}{|c|}{$\begin{array}{l}\text { Tratamentos } \\
\text { Treatments }\end{array}$} \\
\hline & $\begin{array}{c}\mathrm{NT} \\
\text { Control }\end{array}$ & $\begin{array}{c}\mathrm{NH}_{3} \\
(3,0 \% \text { da MS }) \\
\mathrm{NH}_{3} \\
(3.0 \% \mathrm{DM})\end{array}$ & $\begin{array}{c}\text { Uréia } \\
(5,0 \% \text { da MS }) \\
\text { Urea } \\
(5.0 \% \quad D M)\end{array}$ \\
\hline $\begin{array}{l}\mathrm{N} \text { total adicionado } \\
(\% \text { da } \mathrm{MS}) \\
\text { Applied } N\end{array}$ & o & 2,46 & 2,25 \\
\hline $\begin{array}{l}\mathrm{N} \text { total }(\% \mathrm{MS}) \\
\text { Total } N\end{array}$ & 0,45 & 1,55 & 1,92 \\
\hline $\begin{array}{l}\mathrm{N} \text { fixado }(\% \mathrm{MS}) \\
\text { Fixed } N\end{array}$ & - & 1,10 & 1,47 \\
\hline $\begin{array}{l}\mathrm{N} \text { fixado } \\
(\% \text { do adicionado) } \\
\text { Fixed } N \\
(\% \text { of applied } N)\end{array}$ & ) & 44,71 & 65,33 \\
\hline
\end{tabular}

uréia utilizada e com o conteúdo de umidade da forragem.

A amonização utilizando $\mathrm{NH}_{3}$ ou uréia aumentou significativamente $(\mathrm{P}<0,05)$ a DIVMS dos fenos em 12,06 e 6,64 unidades percentuais, respectivamente (Tabela 1).

O incremento observado na DIVMS provavelmente se deva às modificações na composição química da fração fibrosa, com a diminuição no conteúdo de FDN e de hemicelulose (Tabela 1) o que certamente disponibilizou carboidratos prontamente digestíveis para os microrganismos do rúmen. Associado a estas modificações, o aumento de nitrogênio disponível propicia melhores condições de desenvolvimento para as bactérias do rúmen o que aumenta a digestibilidade da forragem.

Reis et al. (1995a), estudando a amonização do feno de capim $B$. brizantha, verificaram aumento na DIVMS de 20,8 e 15,0 unidades percentuais, respectivamente para os fenos tratados com $\mathrm{NH}_{3}$ e uréia. O resultado obtido no presente trabalho é muito semelhante ao obtido por Rosa et al. (1998) utilizando uréia para o tratamento do feno de $B$. decumbens ( $5,4 \%$ da MS), pois encontraram aumento na DIVMS de 7,6 unidades percentuais. O menor incremento na DIVMS observado no feno tratado com uréia pode 
estar associado a menor modificação na fração fibrosa, obtida neste tratamento. Este fato pode estar associado ao alto conteúdo de MS (93\%) do feno por ocasião do tratamento e a pequena inclusão de água no momento do tratamento. Dolberg (1992) demonstrou que a maior eficiência do tratamento com uréia pode ser obtida, quando a forragem possui umidade de $30,0 \%$, e a uréia é aplicada na dosagem de 4,0 a $8,0 \%$ em relação a MS do feno.

No presente estudo, optou-se por adicionar água a fim de se elevar o conteúdo de umidade para 20,0\%. Tal fato deve-se a questões de ordem prática, uma vez que devido ao peso das pilhas de fardos (3720 kg de MS), resultaria na aplicação de elevado volume de água com o intuito de se obter feno com $30,0 \%$ de umidade. Tal decisão pode ter comprometido a eficiência do tratamento com uréia, afetando a distribuição e possivelmente a hidrólise da uréia.

Analisando-se conjuntamente os dados referentes à composição química do feno não tratado avaliado no presente experimento (Tabela 1), pode-se verificar que é alto o teor dos constituintes da parede celular e baixos são os teores de PB e a DIVMS, evidenciando a baixa qualidade de gramíneas tropicais colhidas após o florescimento.

A análise dos dados da Tabela 3 mostra que a amonização promoveu aumento significativo $(\mathrm{P}<0,05)$ no consumo de MS dos animais alimentados com feno tratado com $\mathrm{NH}_{3}$ e suplementados com milho $(1,147 \mathrm{~kg} /$ dia de MS). Os animais alimentados com feno tratado com uréia e suplementados com milho $(1,147 \mathrm{~kg} / \mathrm{dia}$ de MS) apresentaram o mesmo consumo de MS $(\mathrm{P}>0,05)$ comparado àqueles que receberam feno não tratado e suplementado com farelo de soja (1,08 kg/dia de MS).
O aumento verificado no consumo de MS observado nos animais que receberam feno tratado com $\mathrm{NH}_{3}$ foi de $12,8 \%$, está compatível com o resultado do estudo de Reis et al. (1995b) que desenvolveram trabalho com feno de braquiária brizantha amonizado.

Não se observou aumento no consumo de MS nos animais alimentados com fenos tratados com uréia, o que pode ser explicado pela não melhoria na digestibilidade em resposta ao tratamento (Tabela 1). No presente experimento, o tratamento com uréia não promoveu as modificações no valor nutritivo proporcionadas pelo tratamento com $\mathrm{NH}_{3}$ (Tabela 1). A não observação de aumento no consumo de MS, proporcionado pelo tratamento com uréia, pode estar relacionada com a pequena alteração nos constituintes da parede celular e na digestibilidade da MS, aumentando o tempo de retenção do alimento no trato digestivo e, portanto, limitando o consumo de MS.

Reis et al. (1995b) e Rosa et al. (1996) verificaram aumento em torno de $23 \%$ no consumo de MS, em resposta à amonização. A revisão de Berger et al. (1994) reforça o resultado obtido neste experimento para o feno tratado com $\mathrm{NH}_{3}$, registrando que em 21 trabalhos de pesquisa utilizando resíduos de culturas tratados com amônia, houve aumento no consumo de MS de $22 \%$.

A análise dos dados (Tabela 3) evidencia que os ganhos de peso dos animais que receberam feno não tratado, suplementado com farelo de soja $(1,08 \mathrm{~kg} / \mathrm{dia}$ de MS) e feno tratado com $\mathrm{NH}_{3}$ suplementado com milho $(1,147 \mathrm{~kg} / \mathrm{dia}$ de MS) não apresentaram diferença significativa $(\mathrm{P}>0,05)$. $\mathrm{O}$ feno tratado com uréia, suplementado com milho (1,147 kg/dia de MS), propiciou ganho de peso significativamente inferior quando comparado com os animais alimentados com

Tabela 3 - Consumo de matéria seca (CMS), ganho de peso (GP) e conversão alimentar (CA) de bovinos alimentados com os fenos de Brachiaria decumbens amonizados

Table 3 - Dry matter intake (DMI), weight gain (WG), feed conversion (FC) of steers fed different ammoniated Brachiaria decumbens hays

\begin{tabular}{|c|c|c|c|}
\hline $\begin{array}{l}\text { Tratamentos } \\
\text { Hays }\end{array}$ & $\begin{array}{l}\text { CMS }(\% \mathrm{PV}) \\
D M I(\% B W)\end{array}$ & $\begin{array}{l}\mathrm{GP}(\mathrm{kg} / \mathrm{dia}) \\
W G(\mathrm{~kg} / \text { day })\end{array}$ & $\begin{array}{l}\mathrm{CA}(\mathrm{kg} \mathrm{MS} / \mathrm{kgGP}) \\
F C(K g D M / \mathrm{kg} \mathrm{WG})\end{array}$ \\
\hline $\begin{array}{l}\mathrm{NT}+\text { farelo soja }(1,08 \mathrm{kgMS} / \mathrm{dia}) \\
\text { Control + soybean meal }(1.08 \mathrm{~kg} D M / d a v)\end{array}$ & $1,97^{b}$ & $0,60^{\mathrm{a}}$ & $10,76^{\mathrm{a}}$ \\
\hline $\begin{array}{l}\mathrm{NH}_{3}+\text { milho }(1,114 \mathrm{kgMS} / \mathrm{dia}) \\
\mathrm{NH}_{3}+\text { corn meal }(1.114 \mathrm{~kg} \mathrm{DM} / \text { day })\end{array}$ & $2,23^{\mathrm{a}}$ & $0,53^{\mathrm{a}}$ & $12,76^{\mathrm{a}}$ \\
\hline $\begin{array}{l}\text { Uréia + milho }(1,114 \mathrm{~kg} \mathrm{MS} / \text { dia }) \\
\text { Urea }+ \text { corn meal }(1.114 \mathrm{~kg} \text { DM/day })\end{array}$ & $1,90^{\mathrm{b}}$ & $0,37^{\mathrm{b}}$ & $16,87^{b}$ \\
\hline CV $(\%)$ & 7,70 & 16,83 & 15,31 \\
\hline
\end{tabular}

Médias na mesma coluna seguidas de letras iguais, não diferem entre si, pelo teste de Tukey $(\mathrm{P}>0,05)$.

Means followed by the same letter, in the column, do not differ $(P>.05)$

R. Bras. Zootec., v.31, n.3, p.1325-1332, 2002 (suplemento) 
feno não tratado e suplementado com farelo de soja, ou tratado com $\mathrm{NH}_{3}$ e suplementado com milho.

$\mathrm{O}$ resultado observado neste trabalho para o feno tratado com $\mathrm{NH}_{3}$ e suplementado com milho $(1,147 \mathrm{~kg} / \mathrm{dia}$ de MS) está de acordo com o encontrado por Reis et al. (1995b), que não verificaram diferença no ganho de peso, comparando feno não tratado com feno tratado com amônia anidra e suplementado. Este resultado demonstra que o feno amonizado suplementado com fubá de milho propicia desempenho animal semelhante ao obtido com o fornecimento de feno não tratado suplementado com farelo de soja. Esta verificação pode trazer benefícios de ordem econômica, pois diminuiria o custo de produção.

Garcia et al. (1988) observaram desempenho superior para os animais que consumiram palha de arroz tratada com amônia anidra, quando comparados com os animais que consumiram palha de arroz não tratada.

O baixo desempenho dos animais que receberam feno tratado com uréia e suplementado com milho $(1,147 \mathrm{~kg} / \mathrm{dia}$ de MS) pode ser explicado pela menor eficiência deste tratamento em promover modificações na fração fibrosa e na digestibilidade da MS. Estes fatores influenciaram negativamente o consumo, limitando o fornecimento de energia para o animal, tendo como conseqüência menor desempenho.

Com relação à conversão alimentar, como pode ser verificada através dos resultados apresentados na Tabela 3, a amonização utilizando a $\mathrm{NH}_{3}$ não promoveu diferença significativa $(\mathrm{P}>0,05)$, enquanto observou-se no feno tratado com uréia aumento significativo nos valores. A maior quantidade de MS ingerida para produção de $1 \mathrm{~kg}$ de peso vivo se deve ao menor desempenho e ao menor consumo de MS dos animais alimentados com feno tratado com uréia, estando diretamente relacionados com as modificações observadas no valor nutritivo em função da amonização.

Da mesma forma, Pereira et al. (1990) também observaram melhor conversão alimentar para os animais que receberam palha de milho tratada. Trabalhando em condições climáticas semelhantes, Reis et al. (1995b) também não verificaram diferença na conversão alimentar de bovinos alimentados com palha de arroz e o feno de braquiária brizantha tratados com $\mathrm{NH}_{3}$ e não tratados.

Neste estudo observou-se uma produção de 1,68; 1,49 e 1,04 arrobas, proporcionando custo de alimentação de $\mathrm{R} \$ 55,38 ; \mathrm{R} \$ 84,55 ; \mathrm{R} \$ 46,33 /$ bovino em 84 dias, respectivamente para os bovinos alimentados com feno não tratado (suplementado com farelo de soja), tratado com $\mathrm{NH}_{3}$ (suplementado com milho) e tratado com uréia (suplementado com milho).

Analisando estes dados (Tabela 4), e considerando o preço pago pela arroba de $\mathrm{R} \$ 42,00$, tem-se uma receita bruta por bovino de $\mathrm{R} \$ 70,56 ; \mathrm{R} \$ 62,58$ e $\mathrm{R} \$$ 43,68 , respectivamente para os bovinos alimentados com o feno não tratado e suplementados com farelo de soja, tratado com $\mathrm{NH}_{3}$ e suplementados com milho, e tratado com uréia suplementados com milho. Esta receita bruta comparada com o custo de produção permitiria uma receita líquida de $\mathrm{R} \$ 9,03 /$ arroba para os bovinos alimentados com feno não tratado mais farelo de soja e prejuízo de $\mathrm{R} \$ 14,76$ e $\mathrm{R} \$ 2,54$ por arroba respectivamente para os bovinos alimentados com fenos tratados com $\mathrm{NH}_{3}$ ou uréia.

Estes dados enfatizam que o processo de amonização utilizando $\mathrm{NH}_{3}$, apesar dos resultados de desempenho, torna-se de difícil aplicação devido ao alto custo do processo. No caso do tratamento com uréia, se forem resolvidos os problemas inerentes à eficiência do tratamento, o que proporcionaria desempenho semelhante ao

Tabela 4 - Custo de produção da arroba - @ (CP), receita bruta (RB) e balanço financeiro(BF), de bovinos alimentados com rações a base de fenos de Brachiaria decumbens

Table 4 - Production cost (@), income, and financial balance (FB) of the steers fed with ammoniated Brachiaria decumbens hays

\begin{tabular}{|c|c|c|c|}
\hline $\begin{array}{l}\text { Tratamentos } \\
\text { Treatments }\end{array}$ & $\begin{array}{l}\mathrm{CP}(\mathrm{R} \$ / @) \\
P C(R \$ / @)\end{array}$ & $\begin{array}{c}\mathrm{RB}(\mathrm{R} \$ / @) \\
\text { Income }(R \$ / @)\end{array}$ & $\begin{array}{l}\mathrm{BF}(\mathrm{R} \$ / @) \\
F B(R \$ / @)\end{array}$ \\
\hline $\mathrm{NT}+$ farelo soja $(1,08 \mathrm{~kg} \mathrm{MS} / \mathrm{dia})$ & 32,96 & 42,00 & 9,03 \\
\hline $\begin{array}{l}\text { Control }+ \text { soybean meal }(1.08 \mathrm{~kg} \mathrm{DM} / \text { day }) \\
\mathrm{NH}_{3}+\text { milho }(1,114 \mathrm{~kg} \mathrm{MS} / \text { dia }) \\
\mathrm{NH}_{3}+\text { corn meal }(1.114 \mathrm{~kg} \mathrm{DM} / \text { day })\end{array}$ & 56,76 & 42,00 & $-14,76$ \\
\hline $\begin{array}{l}\text { Uréia + milho }(1,114 \mathrm{kgMS} / \text { dia }) \\
\text { Urea }+ \text { corn meal }(1.114 \mathrm{~kg} \text { DM/day })\end{array}$ & 44,54 & 42,00 & $-2,54$ \\
\hline
\end{tabular}

R. Bras. Zootec., v.31, n.3, p.1325-1332, 2002 (suplemento) 
verificado com amônia anidra, viabilizaria a sua utilização, pois seu custo de produção é menor (Tabela 4), permitindo melhor desempenho econômico. Para tanto, devem-se estudar formas de aplicação que resultem em melhores resultados sobre o valor nutritivo e a qualidade, ou seja, desempenho de animais alimentados com volumosos tratados com uréia.

\section{Conclusões}

A amonização do feno de Brachiaria decumbens com $\mathrm{NH}_{3}$ foi um processo eficiente para melhorar a qualidade do volumoso, proporcionando aumento no consumo de matéria seca e ganho de peso semelhante ao observado com os bovinos alimentados com feno suplementados com farelo de soja.

O processo de amonização utilizando uréia não melhorou a qualidade do volumoso, fato que prejudicou o consumo de matéria seca e o ganho de peso de bovinos alimentados com feno amonizado com uréia, suplementados com milho grão moído.

\section{Literatura Citada}

AGRICULTURAL AND FOOD RESEARCH COUNCILAFRC. Energy and protein requirements of ruminants. Farnham Royal: CAB International, 1995. 59p.

BERGER, L.L.; FAHEY JR., G.C.; BOURQUIM, L.O. et al. Modification of forage quality after harvest. In: FAHEY Jr., G.C. et al. (Ed.). Forage quality, evaluation e utilization. Madison: American Society of Agronomy, 1994. p.922966.

BONJARDIN, S.R.; REIS, R.A.; RODRIGUES, L.R.A. et al. Avaliação da qualidade dos fenos de gramíneas tropicais armazenados com diferentes níveis de umidade e tratados com amônia. Revista Brasileira de Zootecnia, v. 21, n.5, p.866-873, 1992.

DOLBERG, F. Program in the utilization of urea-ammonia treated crop residues: nutritional dimensions and apllication of the technology on small farm. In: SIMPÓSIO INTERNACIONAL DE RUMINANTES, 1992, Lavras. Anais... Lavras: Sociedade Brasileira de Zootecnia, 1992. p.130-145.

GARCIA, R.; OLIVEIRA, L.A.V.; FONTES, C.A.A.et al. Utilização do feno de palha de arroz tratado com amônia anidra na alimentação de bovinos em confinamento. In : REUNIÃO ANUAL DA SOCIEDADE BRASILEIRA DE ZOOTECNIA, 25., 1988, Viçosa. Anais...Viçosa: Sociedade Brasileira de Zootecnia, 1988, p.206.

PEREIRA, J.C.; QUEIROZ, A.C.; MATOSO, J. et al. Efeito do tratamento da palha de milho com uréia ou amônia anidra, sobre o consumo de matéria seca e digestibilidade aparente dos nutrientes. Revista Brasileira de Zootecnia, v. 21, n.2, p.262-269, 1990.
PEREIRA, J.R.A.; EXEQUIEL, J.M.B.; REIS, R.A. et al. Efeitos da amonização sobre o valor nutritivo do feno de capim braquiária. Pesquisa Agropecuária Brasileira, v. 28, n.12, p.1451-1455, 1993.

QUEIROZ, A.C.; LEMENAGER, R.P.; HENDRIX, K.S. et al. Efeito do tratamento da palha de trigo com amônia anidra sobre a proteína bruta, digestibilidade in vitro da matéria seca e os componentes da fibra, após vários tempos de amonização e período de aeração. Revista Brasileira de Zootecnia, v.21, n.6, p.1020-1028, 1992.

REIS, R.A.; RODRIGUES , L.R.A. Amonização de forrageiras de baixa qualidade.In: SIMPÓSIO BRASILEIRO DE FORRAGEIRAS E PASTAGENS, 1994, Campinas. Anais... Campinas: Colégio Brasileiro de Nutrição Animal, 1994. p.89-105.

REIS, R.A.; RODRIGUES L.R.A.; PEDROSO, P. Avaliação de fontes de amônia para o tratamento de volumosos de baixa qualidade. Revista Brasileira de Zootecnia, v.24, n.4, p.487-493, 1995a.

REIS, R.A.; ANDRADE, P; RODRIGUES, L.R.A. et al. Palha de arroz e feno de Brachiaria brizantha amonizados e suplementados com energia ou proteína na alimentação de bovinos. Revista Brasileira de Zootecnia, v.24, n.5, p. 832$840,1995 \mathrm{~b}$.

ROSA, B.; REIS, R.A.; RESENDE, K.T. et al. Degradabilidade in situ do feno de Brachiária decumbens Stapf cv. Basilisk amonizado. In: REUNIÃO ANUAL DA SOCIEDADE BRASILEIRA DE ZOOTECNIA, 33., 1996, Fortaleza. Anais... Fortaleza: Sociedade Brasileira de Zootecnia, 1996. p.324-326.

ROSA, B.; REIS, R.A.; RESENDE, K.T. et al. Valor nutritivo do feno de Brachiaria decumbens Stapf cv. Basilisk submetido a tratamento com amônia anidra ou uréia. Revista Brasileira de Zootecnia, v.27, n.4, p.815-822, 1998.

SILVA, D.J. Análise de alimentos (métodos químicos e biológicos). 2.ed. Viçosa, MG: Universidade Federal de Viçosa, 1990. 165p.

SUNDSTOL , F.; COXWORT, E.M. Ammonia treatment. In: SUNDSTOL, F.; OWEN, E. (Eds.) Straw and others fibrous by products as feed. Amsterdam: Elsevier Press, 1984. p.196-247.

Van SOEST, P.J.; FERREIRA, A.M.; HARTLEY, R.D. Chemical properties in relation to nutritive quality of ammonia treatment forages. Animal Feed Science and Technology, v.10, n.2, p.155-164, 1983. 